\title{
Clinically Beneficial Application of Flash Glucose Monitoring (FGM)
}

\author{
Hiroshi Bando* \\ Medical Research, Japan

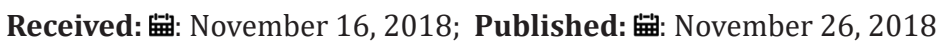 \\ *Corresponding author: Hiroshi Bando, Medical Research, Nakashowa 1-61, Tokushima 770-0943, Japan
}

Keywords: Flash Glucose Monitoring; Continuous Glucose Monitoring; Freestyle Libre; Blood Glucose Monitoring System; Morbus Value; Glucose Variability

Abbreivations: FGM: Flash Glucose Monitoring; CGM: Continuous Glucose Monitoring; FSL: FreeStyle Libre; BGMS: Blood Glucose Monitoring System; M: Morbus Value; CONGA: Continuous Overall Net Glycaemic Action; MODD: Mean of Daily Differences; MAGE: Mean Amplitude Of Glycaemic Excursions; DG5: Dexcom_G5; CR: Calorie Restriction; LCD: Low Carbohydrate Diet; RCT: Randomized Controlled Trials

\section{Introduction}

For the treatment of diabetes, it is important to manage glucose variability and to prevent microvascular complications as well as long-term macrovascular disease [1]. HbA1c has been the gold standard for monitoring glucose control and for decreasing hyperglycemia, with the recommendation of strict targets of HbA1c [2]. Recently, the discussion on the target value of HbA1c value has been found. Since HbA1c value is reflected by the mean value of blood glucose, daily blood variability must be fundamentally improved. In recent years, Continuous glucose monitoring (CGM) has been an important apparatus in artificial pancreas systems and also evaluating blood glucose variability [3]. After that, a real-time CGM (rtCGM) system was developed and it has been called Flash glucose monitoring (FGM) [4]. In the light of blood glucose values, there were considerable agreements between CGM and FGM, and FGM has been applied and developed in the clinical diabetic practice [5]. Although similar to conventional CGM, several significant beneficial differences are present in FGM. Its sensor is factory calibrated and then does not need calibration with blood glucose testing over 14day lifespan. Furthermore, FGM is also cheaper than that of CGM [6]. In contrast, it lacks the alarm mechanisms and connectivity associated with continuous subcutaneous insulin infusion (CSII). FGM shows validated accuracy and usability in patients with type 1 and 2 diabetes [7].

There have been two FGMs in United States and the European Union, which are Dexcom_G5 (DG5) and FreeStyle Libre (FSL). As to the measurement results, about $25 \%$ results revealed differences from BGM results exceeding $15 \mathrm{mg} / \mathrm{dL}$ or $15 \%$ of the data [8]. In comparison with the blood glucose monitoring system (BGMS), DG5 showed rather slightly smaller deviations than that of FSL
[8]. Further, continuously stored data from FSL were deviated to slightly smaller degree from BGMS results than scanned FSL data [9]. From these findings, the reason why scanned data were different from stored data and how these can influence diabetic treatment would be investigated for future research [9]. When looking back on the clinical practice and research of diabetes, glucose variability in various diseased states have been investigated for years. Several biomarkers include Morbus (M) value [10], mean amplitude of glycaemic excursions (MAGE) [11], continuous overall net glycaemic action (CONGA) [12], mean of daily differences (MODD) [13], and so on. As to M value, authors and colleagues have continued clinical research in patients with diabetic patients, in which glucose variability and glucose profile were clarified in two nutritional therapy with low carbohydrate diet (LCD) and calorie restriction (CR) [14].

In the clinical diabetic practice, FreeStyle Libre (FSL) Flash glucose monitoring (FGM) system (Abbott diabetes Care, Alameda, CA) has been widely used in the world [7]. The performance and usability of FSL were proved to be accurate in comparison with that of capillary blood glucose reference values [7]. By clinical application of FGM, diabetic glucose variability has been improved. According to the randomized controlled trials (RCT) in patients with diabetes, there are increased glucose testing frequency, improved glycemic markers and a reduction of hypoglycemia in both type 1 and 2 diabetic patients [15,16]. Beneficial efficacy were found in type 1 diabetics, in which hypoglycemia was reduced with maintaining good HbA1c. Furthermore in type 2, young diabetics with poor control showed decreased HbA1c $[15,16]$. There was an impressive report by Dunn et al. [17]. Data was enormous, including 
55 thousand readers, 64 million scan data and 392 million glucose data for 21 months. The situation of daily scans were shown as follows:

a. Scans were found more than 10 times in $75 \%$ of the reader,

b. Frequency of scan is 5 times more in daytime than night,

c. Frequency of scan is stable during $1000 \mathrm{~h}$ to $2000 \mathrm{~h}$,

d. Most frequent scan was observed during 2000-2100h [17].

There were beneficial results in the following:

a. Estimated $\mathrm{HbA1c}$ gradually reduced from $8.0 \%$ to $6.7 \%$ $(\mathrm{p}<0.001)$,

b. Time period of glucose below $70,56,45 \mathrm{mg} / \mathrm{dL}$ were decreased by $15 \%, 40 \%, 49 \%$, respectively (all $\mathrm{p}<0.001$ ),

c. Time period more than $180 \mathrm{mg} / \mathrm{dL}$ were decreased 10.4 to 5.7 hours a day $(44 \%, \mathrm{p}<0.001)$. These effective results were consistent across different 46 countries [17].

Glucose control measures by glucose check frequency were investigated. There were linear relationship between the number of times for scans per day and estimated HbA1c value. The data were in the following: As the number is 5, 10, 30, 50 times a day, estimated $\mathrm{HbA1c}$ was $8.0 \%, 7.4 \%, 6.9 \%, 6.7 \%$, and time period of blood glucose more than $180 \mathrm{mg} / \mathrm{dL}$ was $10.5 \mathrm{~h}, 8.5 \mathrm{~h}, 6.6 \mathrm{hr}, 5.9$ hours per day, respectively [17]. From these findings, FMG can allow frequent glucose checks automatically with beneficial efficacy of glucose variability such as increased time in adequate range and reduced time in hyper and hypoglycemia. In summary, this article described the topic of recent topic of FGM and changing concept of beneficial management of diabetic practice and research. In other words, FGM could become the fourth treatment method of diabetes, as well as diet, exercise and medicine.

\section{References}

1. Patel A, MacMahon S, Chalmers J, Neal B, Billot L, et al. (2008) Intensive Blood Glucose Control and Vascular Outcomes in Patients with Type 2 Diabetes. N Engl J Med 358(24): 2560-2572.

2. American Diabetes Association (2017) Glycemic Targets Diabetes Care 40 (Suppl 1): S48-S56.

3. Thabit H, Leelarathna L, Wilinska ME, Daniella Elleri, Janet M Allen, et al. (2015) Accuracy of continuous glucose monitoring during three closedloop home studies under free-living conditions. Diabetes Technol Ther 17(11): 801-807.
4. Dover AR, Stimson RH, Zammitt NN, Gibb FW (2017) Flash Glucose Monitoring Improves Outcomes in a Type 1 Diabetes Clinic. J Diabetes Sci Technol. 11(2): 442-443.

5. Bonora B, Maran A, Ciciliot S, Avogaro A, Fadini GP (2016) Head-to-head comparison between flash and continuous glucose monitoring systems in outpatients with type 1 diabetes. J Endocrinol Invest 39(12): 13911399.

6. Heinemann L, Freckmann G (2015) CGM versus FGM; or, continuous glucose monitoring is not flash glucose monitoring. J Diabetes Sci Technol 9(5): 947-950.

7. Bailey T, Bode BW, Christiansen MP, Klaff LJ, Alva S (2015) The performance and usability of a factory-calibrated flash glucose monitoring system. Diabetes Technol Ther 17(11): 787-794.

8. Freckmann G, Link M, Pleus S, Westhoff A, Kamecke U, et al. (2018) Measurement Performance of Two Continuous Tissue Glucose Monitoring Systems Intended for Replacement of Blood Glucose Monitoring. Diabetes Technol Ther 20(8): 541-549.

9. Pleus S, Kamecke U, Link M, Haug C, Freckmann G (2018) Flash glucose monitoring: differences between intermittently scanned and continuously stored data. J Diabetes Sci Technol 12(2): 397-400.

10. Schlichtkrull J, Munck O, Jersild M (1965) The M-valve, an index of bloodsugar control in diabetics. Acta Med Scand 177: 95-102.

11. Service FJ, Molnar GD, Rosevear JW, Ackerman E, Gatewood LC, et al. (1970) Mean amplitude of glycemic excursions, a measure of diabetic instability. Diabetes 19(9): 644-655.

12. McDonnell CM, Donath SM, Vidmar SI, Werther GA, Cameron FJ (2005) A novel approach to continuous glucose analysis utilizing glycemic variation. Diabetes Technol Ther 7(2): 253-263.

13. Molnar GD, Taylor WF, Ho MM (1972) Day-to-day variation of continuously monitored glycaemia: a further measure of diabetic instability. Diabetologia 8(5): 342-348.

14. Bando H, Ebe K, Muneta T, Bando M, Yonei Y (2017) Effect of low carbohydrate diet on type 2 diabetic patients and usefulness of M-value. Diabetes Res Open J 3(1): 9-16.

15. Bolinder J, Antuna R, Geelhoed Duijvestijn P, Kröger J, Weitgasser R (2016) Novel glucose-sensing technology and hypoglycaemia in type 1 diabetes: a multicentre, non-masked, randomised controlled trial. Lancet 388(10057): 2254-2263.

16. Haak T, Hanaire H, Ajjan RA, Hermanns N, Riveline JP, et al. (2017) Flash glucose-sensing technology as a replacement for blood glucose monitoring for the management of insulin-treated type 2 diabetes: a multicenter, open-label randomized controlled trial. Diabetes Ther 8(1): 55-73.

17. Dunn TC, Xu Y, Hayter G, Ajjan RA (2018) Real-world flash glucose monitoring patterns and associations between self-monitoring frequency and glycaemic measures: A European analysis of over 60 million glucose tests. Diabetes Res Clin Pract 137: 37-46. 
ISSN: 2574-1241

DOI: 10.26717/BJSTR.2018.11.002095

Hiroshi Bando. Biomed J Sci \& Tech Res

(C) (P) This work is licensed under Creative

Submission Link: https://biomedres.us/submit-manuscript.php

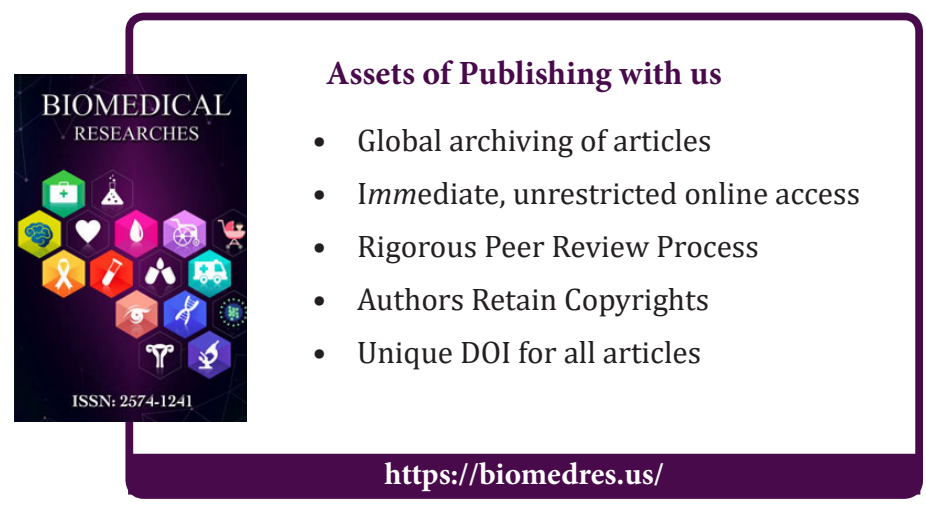

